\title{
Association of cleft lip and palate on mother-to-infant bonding: a cross-sectional study in the Japan Environment and Children's Study (JECS)
}

Shinobu Tsuchiya ${ }^{1}$, Masahiro Tsuchiya ${ }^{2^{*}}$ (D), Haruki Momma ${ }^{3}$, Takeyoshi Koseki ${ }^{4}$, Kaoru Igarashi ${ }^{1,5}$, Ryoichi Nagatomi ${ }^{3,6}$, Takahiro Arima ${ }^{7}$, Nobuo Yaegashi $^{8}$ and Japan Environment \& Children's Study Group

\begin{abstract}
Background: Cleft lip and/or palate is among the most prevalent congenital birth defects, and negatively affects maternal psychological status and may consequently result in higher prevalence of child maltreatment. However, the association of childbirths of infants with cleft lip and/or palate with maternal emotional involvement still remains unclear. We examined the association between childbirths of infants with cleft lip and/or palate and mother-to-infant bonding, using data from the Japan Environment and Children's Study, a nationwide birth cohort study.

Methods: A cross-sectional study using the jecs-an-20,180,131 dataset was performed. A total 104,065 fetuses in 15 regional centres in Japan were enrolled after obtaining informed written consent. The Mother-to-Infant Bonding Scale, a self-report scale consisting of 10 items, was used to evaluate maternal bonding at one year after childbirth. Finally, the participants consisted of 79,140 mother-infant pairs, of which 211 mothers of infants with cleft lip and/ or palate were included in our analyses. Multivariable logistic regression analysis using multiple imputation for missing data was performed to calculate the odds ratio and 95\% confidence interval in the estimation of the association between bonding disorders and childbirths with cleft lip and/or palate.
\end{abstract}

Results: No increased risk of bonding disorders was observed among all the mothers of infants with cleft lip and/or palate (odds ratio [95\% confidence interval]; 0.97 [0.63-1.48], $p=0.880$ ), however, advanced maternal age or multiple parity may adversely affect the associations between bonding disorders and cleft lip and/or palate, respectively. After stratification with a combination of maternal age and parity, a significant association of cleft lip and/or palate with bonding disorders was found only among advanced-age multiparae (odds ratio [95\% confidence interval] $=2.51[1.17-5.37], p=0.018$ ), but it was weakened after additional adjustment for maternal depression.

Conclusions: Childbirths of infants with cleft lip and/or palate may increase the risk of bonding disorders among advanced-age multiparae, possibly through maternal depression. This finding provides valuable information for the provision of multidisciplinary cleft care.

Keywords: Cleft lip and/or palate, Mother-to-infant bonding, Nationwide birth cohort, Psychological distress, Crosssectional study

\footnotetext{
* Correspondence: tsuchiya-thk@umin.ac.jp

2Department of Nursing, Tohoku Fukushi University, 6-149-1 Kunimi-ga-oka,

Aoba-ku, Sendai, Miyagi 981-3201, Japan

Full list of author information is available at the end of the article
}

(c) The Author(s). 2019 Open Access This article is distributed under the terms of the Creative Commons Attribution 4.0 International License (http://creativecommons.org/licenses/by/4.0/), which permits unrestricted use, distribution, and reproduction in any medium, provided you give appropriate credit to the original author(s) and the source, provide a link to the Creative Commons license, and indicate if changes were made. The Creative Commons Public Domain Dedication waiver (http://creativecommons.org/publicdomain/zero/1.0/) applies to the data made available in this article, unless otherwise stated. 


\section{Background}

Cleft lip and/or cleft palate $(\mathrm{CL} / \mathrm{P})$, namely cleft lip with or without cleft palate $(C L \pm P)$, and isolated cleft palate (CP) are among the most common birth defects and happen at a rate of approximately 1 in 700 births [1]. A nationwide survey in Japan showed that the prevalence of CL/P per 10,000 births was in a range of 14.4-24.8 [1-3], which is higher than the global prevalence. CL/P can be repaired with craniofacial plastic surgeries [2, 4]; however, parents of infants with $\mathrm{CL} / \mathrm{P}$ generally suffer from parenting and/or caregiving issues as a result of lower infant weight gain due to difficulties in direct breastfeeding and higher risk for upper respiratory infection [5-7]. Mothers of infants with CL/P reportedly tend to show negative moods such as depression and anxiety $[8,9]$. Johns et al. found a higher tendency of postpartum depression among older mothers of infants with CL/P [9].

Importantly, Van Horne et al. reported that children with $\mathrm{CL} / \mathrm{P}$ have higher prevalence rates $(7.62 \%$ as cumulative probability) of child maltreatment in the U.S. state of Texas, compared with children with congenital diseases such as Down syndrome and spina bifida (approximately 5\%) [10]. Most of this maltreatment was in the form of supervisory neglect (about 70\%); however, a significantly higher risk of medical neglect was also observed $[10,11]$. Boztepe et al. also indicated that, in comparison with congenital heart disease, cleft lip was more likely to adversely affect maternal emotional connection toward the infant possibly due to the visual aspects of the condition [12]. Indeed, there is increasing evidence suggesting potential impairments of infantmaternal relationships among children with $\mathrm{CL} / \mathrm{P}$ [13-15]. However, the association of childbirths of infants with $\mathrm{CL} / \mathrm{P}$ on maternal emotional involvement toward infants still remains unclear.

Attachment theory, proposed by Bowlby consists of bidirectional interactions in mother-infant dyads for making children feel secure [16]. In distinction to the infant's feelings of the attachment, maternal affectionate feelings toward the infant during the perinatal period has been referred to as "mother-to-infant bonding" [17-19]. Bonding disorders, less maternal affection and behaviour toward the infant, have been acknowledged as predictors of impairment in infant development due to child maltreatment [18-21]. Recently, the Mother-toInfant Bonding Scale (MIBS), which is based on Kumar's Mother-Infant Bonding Questionnaire [17], has been used for quantitative screening of bonding disorders in mother-infant dyads among the general population [22]. Recent cohort studies, including longitudinal studies, have provided increasingly more evidence [19, 23]. Brockington et al. found that bonding disorders were diagnosed in $29 \%$ of mothers with maternal postpartum depression. Indeed, as associated with lifestyle behaviours (drinking and smoking habits) [24], the parity status impacts mother-to-infant bonding because of more requirements regarding maternal attention, especially when a new infant with congenital diseases arrives [25, 26]. Thus, the parity status would confound mother-toinfant bonding with CL/P. Taken together, a better understanding the antecedents of maternal bonding issues after giving birth to a child with $\mathrm{CL} / \mathrm{P}$ will promote developments in multidisciplinary cleft care.

The aim of this study was to investigate the influence of childbirths of infants with CL/P on bonding disorders using a large-scale sample of the Japan Environment and Children's Study (JECS), a nationwide, multicentre, prospective birth cohort in Japan and the MIBS.

\section{Methods}

\section{Study design and participants}

The present study is based on the jecs-an-20,180,131 dataset, which was released in March 2018. In brief, pregnant women in their first trimester were recruited at the first prenatal examination in cooperating hospitals or at local government offices from January 2011 until March 2014. After obtaining informed written consent, participants completed self-administered and medical records/transcripts, and subsequently underwent clinical measurements by medical doctors and trained nurses. To confirm the health status, check-up for both mother and infant was conducted at delivery and one month later. We enrolled 104,065 fetuses in 15 regional centres in JECS. In the fixed data of the JECS, 3921 were miscarriages, stillbirths, and unknown; 1889 were multiple births. Among the 98,255 mother-infant pairs, 10,045 pairs did not reply to the questionnaire sent out at one year after childbirth, and 9070 pairs with other congenital disease(s) without CL/P were excluded from the analysis. A final sample size of 79,140 mother-infant pairs was included in this study (Fig. 1).

\section{Prevalence of CL/P (exposure measure)}

The data on CL/P and other congenital anomalies were ascertained from medical records/transcripts, which were filled by a doctor, a midwife, a nurses or a trained research coordinator at delivery and at one month of age onto JECS transcription forms [3, 27, 28]. The details of data processing, validation, and verification with regards to congenital anomalies were previously described [3]. There are three types of CL/P: cleft lip, cleft palate, or cleft lip with palate. A checkbox for each type was listed on the transcription form. A tick was entered into the corresponding checkbox when any interests of CL/P were observed. Using the fixed JECS dataset, Mezawa et al. reported that total prevalence rates of CL/P per 10 , 000 births was 24.8 [3]. 


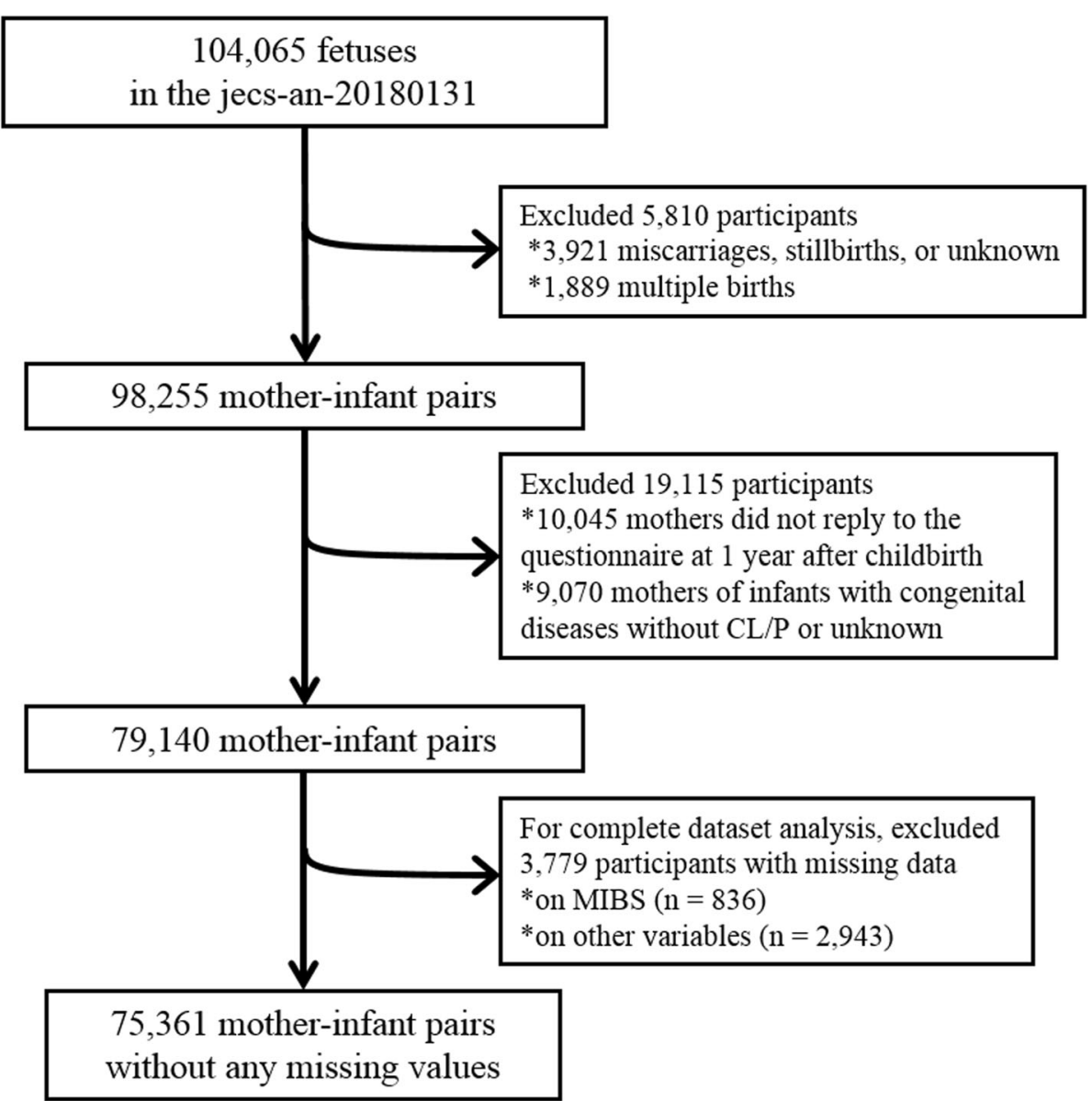

Fig. 1 Flow chart of the study participants. MIBS = Mother-to-Infant Bonding Scale

Furthermore, to examine the influence of visibility of $\mathrm{CL} / \mathrm{P}$ on the mother-to-infant bonding, the mothers of infants with CL/P were divided into two groups: (1) CL \pm $P$ group (mothers of infants with cleft lip with or without cleft palate) and (2) CP group (mothers of infants with isolated cleft palate) as a group with less visible issues.

\section{Mother-to-infant bonding scale (MIBS: outcome measure)} The MIBS is a self-report scale consisting of 10 items with responses based on a four-point scale (from 0 to 3 ), and is used to evaluate mother-to-infant bonding at one year after childbirth. The total score ranges from 0 to 30 , and higher scores indicate worse mother-to-infant bonding. The MIBS had been translated into Japanese and validated in a previous study [22]. Cronbach's alpha of the MIBS for the current sample was 0.73. Because the optimal cut-off score is $4 / 5$ [18], the presence of bonding disorders in mother-infant dyads was defined as $\geq 5$ in this study.

\section{Covariates}

In addition to maternal smoking during pregnancy, maternal drinking habits during pregnancy was assessed with a self-administered questionnaire [29]. Maternal age at delivery, parity, and infant sex were ascertained from medical records/transcripts filled by doctors, midwifes, nurses, or trained research coordinators. In a follow-up questionnaire after childbirth, participants also reported feeding pattern and Kessler Psychological Distress Scale scores (K6) at one year after childbirth. The design of the questionnaire has been previously described in detail $[27,28,30]$.

Using the data from self-administered and medical records/transcripts, an advanced-age mother was defined as $\geq 35$ years old [31]. In addition, participants were categorized into the following groups by parity ('primipara' or 'multipara'). Smoking status was divided into three categories: 'never', 'stopped smoking before or during pregnancy', or 'current smoking'. Alcohol consumption was divided into three categories: 'never', 'stopped drinking', or 'current drinking'. Categories for infant sex were 
'male' or 'female', and categories for feeding pattern were 'breastfeeding', 'formula', or 'mixed'.

\section{Statistical analysis}

Continuous variables were presented as medians with interquartile ranges, and categorical variables were presented as numbers and percentages (Table 1). With regard to missing data, we applied the 'missing at random' assumption, and used multiple imputation with the multivariate normal imputation method [32]. The numbers of participants with missing data in each of the variables are shown in Additional file 1: Table S1. An imputation model including all variables were independently applied for 10 copies of the data, each with missing values suitably imputed. Estimates of the variables were averaged to compute a single mean estimate and adjusted standard errors using Rubin's rule [33]. We performed crude and multivariate logistic regression analyses using the hierarchical multiple regression model for potential covariates to examine the association of bonding disorders with the prevalence of $\mathrm{CL} / \mathrm{P}$ within each subgroup. These analyses were performed after adjustment for potential confounding factors, including maternal smoking and drinking habits, feeding pattern, and infant sex (model 1). All parameters in model 1 plus maternal depression (model 2) were included. The OR and 95\% CI were calculated for bonding disorders. The results of the multiple imputation analyses are shown in Tables 2 and 3. All statistical analyses were performed using SPSS (version 24.0; IBM Corp., Armonk, NY, USA). In the analysis of the data, $P$ values $<0.05$ were considered statistically significant.

\section{Results}

\section{Participants' baseline characteristics}

The median age of the participants was 31 years (interquartile range: $28-35$ years), and the mean MIBS and K6 scores were 1.94 (standard deviation [SD]: 2.29) and 2.79 (SD: 3.61), respectively (Additional file 1: Table S1). The total numbers (\%) of infants born with cleft lip with or without palate or isolated cleft palate in the present study were 64 (0.08), $90(0.11)$, and 57 (0.07), respectively. Interestingly, the mean maternal MIBS scores (SD) of dyads with infants with $\mathrm{CL} / \mathrm{P}$ were similar to those of the healthy infants $(2.13$ [2.72] vs. 1.94 [2.29] in Additional file 1: Table S1), but only advanced-age multiparae with infants with $\mathrm{CL} / \mathrm{P}$ at birth showed higher MIBS scores (SD) compared with healthy infants

Table 1 Basic characteristics of participating mothers

\begin{tabular}{|c|c|c|c|c|c|c|c|c|}
\hline \multirow{3}{*}{$\begin{array}{l}\text { maternal age } \\
\text { parity }\end{array}$} & \multicolumn{4}{|l|}{$<35$} & \multicolumn{4}{|l|}{$\geq 35$} \\
\hline & \multicolumn{2}{|l|}{ primiparae } & \multicolumn{2}{|l|}{ multiparae } & \multicolumn{2}{|l|}{ primiparae } & \multicolumn{2}{|l|}{ multiparae } \\
\hline & $\begin{array}{l}\text { Healthy } \\
(n=25,628)\end{array}$ & $\begin{array}{l}C L / P \\
(n=71)\end{array}$ & $\begin{array}{l}\text { Healthy } \\
(n=31,693)\end{array}$ & $\begin{array}{l}\text { CL/P } \\
(n=85)\end{array}$ & $\begin{array}{l}\text { Healthy } \\
(n=6536)\end{array}$ & $\begin{array}{l}\mathrm{CL} / \mathrm{P} \\
(n=18)\end{array}$ & $\begin{array}{l}\text { Healthy } \\
(n=15,072)\end{array}$ & $\begin{array}{l}\text { CL/P } \\
(n=37)\end{array}$ \\
\hline Age, Median (IQR) & $28(26,31)$ & $28(25.7,31)$ & $30(28,32)$ & $30(27,33)$ & $37(36,39)$ & $37.5(36,40)$ & $37(36,39)$ & $37(35.5,38)$ \\
\hline MIBS score, Mean (SD) & $2.23(2.38)$ & $1.75(1.90)$ & $1.74(2.20)$ & $2.02(2.69)$ & $2.21(2.41)$ & $2.14(2.57)$ & $1.74(2.21)$ & $3.08(3.85)$ \\
\hline Bonding disorders $(\geq 5)$ & $3528(13.8)$ & $5(7.0)$ & $3104(9.8)$ & $9(10.6)$ & $895(13.7)$ & $3(16.7)$ & $1503(10.0)$ & $9(24.3)$ \\
\hline K6 score, Mean (SD) & $2.85(3.63)$ & $3.30(4.24)$ & $2.86(3.75)$ & $2.95(4.15)$ & $2.63(3.34)$ & $2.22(2.71)$ & $2.62(3.39)$ & $3.26(4.57)$ \\
\hline Depression ( $\geq 13$ ) & $715(2.8)$ & $2(2.8)$ & $955(3.0)$ & $3(3.5)$ & $128(2.0)$ & $0(0)$ & $299(2.0)$ & $3(8.1)$ \\
\hline \multicolumn{9}{|l|}{ Smoking habit, n (\%) } \\
\hline Never & $15,988(62.4)$ & $41(57.7)$ & $17,665(55.7)$ & $50(58.8)$ & $3983(61.0)$ & $12(66.7)$ & $9153(60.7)$ & $24(64.9)$ \\
\hline Stopped & $8735(34.1)$ & $27(38.0)$ & $12,418(39.2)$ & $30(35.3)$ & 2379 (36.4) & $6(33.3)$ & $5311(35.2)$ & $12(32.4)$ \\
\hline Smoking & 905 (3.5) & $3(4.2)$ & $1610(5.1)$ & $5(5.9)$ & $174(2.7)$ & $0(0)$ & $608(4.0)$ & $1(2.7)$ \\
\hline \multicolumn{9}{|l|}{ Alcohol intake, $n(\%)$} \\
\hline Never & 8332 (32.5) & 26 (36.6) & 11,906 (37.6) & $31(36.5)$ & 2009 (30.7) & 7 (38.9) & $5200(34.5)$ & $15(40.5)$ \\
\hline Stopped & $15,373(60.0)$ & $42(59.2)$ & $16,643(52.5)$ & $43(50.6)$ & 3894 (59.6) & $11(61.1)$ & 7719 (51.2) & $20(54.1)$ \\
\hline Drinking & $1923(7.5)$ & $3(4.2)$ & $3144(9.9)$ & $11(12.9)$ & $633(9.7)$ & $0(0)$ & $2153(14.3)$ & $2(5.4)$ \\
\hline \multicolumn{9}{|l|}{ sex, $n(\%)$} \\
\hline Male & $12,957(50.6)$ & $38(53.5)$ & $16,076(50.7)$ & $48(56.5)$ & $3359(51.4)$ & $11(61.1)$ & 7809 (51.8) & $20(54.1)$ \\
\hline Female & $12,671(49.4)$ & $33(46.5)$ & $15,617(49.3)$ & $37(43.5)$ & 3177 (48.6) & $7(38.9)$ & 7263 (48.2) & $17(45.9)$ \\
\hline \multicolumn{9}{|l|}{ Feeding pattern, $n$ (\%) } \\
\hline Breast & $7442(29.0)$ & $5(7.0)$ & 11,932 (37.6) & $17(20.0)$ & 1220 (18.7) & $0(0)$ & $5346(35.5)$ & $5(13.5)$ \\
\hline Mixed & $17,670(68.9)$ & $53(74.6)$ & $19,008(60.0)$ & $62(72.9)$ & $5146(78.7)$ & $17(94.4)$ & 9344 (62.0) & $26(70.3)$ \\
\hline Formula & $516(2.0)$ & $13(18.3)$ & $753(2.4)$ & $6(7.1)$ & $170(2.7)$ & $1(5.6)$ & $382(2.5)$ & $6(16.2)$ \\
\hline
\end{tabular}


Table 2 Association of bonding disorders with the prevalence of $\mathrm{CL} / \mathrm{P}$

\begin{tabular}{|c|c|c|c|}
\hline$<35$, Primiparae, & Healthy $(n=25,628)$ & $\mathrm{CL} / \mathrm{P}(\mathrm{n}=71)$ & $p$ value \\
\hline Bonding disorders, n (\%) & $3,528(13.8)$ & $5(7.0)$ & \\
\hline Crude & 1.00 & $0.51(0.21-1.26)$ & 0.146 \\
\hline Model $1^{\mathrm{a}}$ & 1.00 & $0.44(0.18-1.09)$ & 0.076 \\
\hline Model $2^{b}$ & 1.00 & $0.44(0.18-1.12)$ & 0.085 \\
\hline$<35$, Multiparae & Healthy $(n=31,693)$ & $\mathbf{C L} / \mathbf{P}(\mathrm{n}=85)$ & $p$ value \\
\hline Bonding disorders, n (\%) & $3,104(9.8)$ & $9(10.1)$ & \\
\hline Crude & 1.00 & $1.11(0.55-2.23)$ & 0.780 \\
\hline Model $1^{a}$ & 1.00 & $1.03(0.51-2.07)$ & 0.946 \\
\hline Model $2^{b}$ & 1.00 & $1.03(0.50-2.10)$ & 0.941 \\
\hline$\geq 35$, Primiparae & Healthy $(n=6,536)$ & $\mathbf{C L} / \mathbf{P}(\mathrm{n}=18)$ & $p$ value \\
\hline Bonding disorders, n (\%) & $895(13.7)$ & $3(16.7)$ & \\
\hline Crude & 1.00 & $1.26(0.67-2.38)$ & 0.714 \\
\hline Model $1^{a}$ & 1.00 & $1.14(0.61-2.15)$ & 0.836 \\
\hline Model $2^{\mathrm{b}}$ & 1.00 & $1.24(0.66-2.33)$ & 0.739 \\
\hline$\geq 35$, Multiparae & Healthy $(n=15,072)$ & $\mathrm{CL} / \mathrm{P}(\mathrm{n}=37)$ & $p$ value \\
\hline Bonding disorders, n (\%) & $1,503(10.0)$ & $9(24.3)$ & \\
\hline Crude & 1.00 & $2.90(1.58-5.34)$ & 0.006 \\
\hline Model $1^{a}$ & 1.00 & $2.51(1.17-5.37)$ & 0.018 \\
\hline Model $2^{b}$ & 1.00 & $2.18(0.96-4.95)$ & 0.062 \\
\hline
\end{tabular}

Odds ratio (95\% confidence interval) (all such values) for bonding disorders were compered with the reference participants

${ }^{a}$ Adjusted for maternal factors (smoking and drinking habits, feeding pattern, and infant sex)

${ }^{\mathrm{b}}$ Additionally adjusted for maternal depression with Model 1

$P$ values representing significant differences $(<0.05)$ are indicated in bold

(3.08 [3.85] vs. 1.74 [2.21]) as well as prevalence of maternal depression (8.1\% vs. $2.0 \%)$, as shown in Table 1.

\section{Association between bonding disorders and $\mathrm{CL} / \mathrm{P}$}

No risk of bonding disorders was observed among all the mothers with infants with $\mathrm{CL} / \mathrm{P}$ (odds ratio [OR] [95\% confidence interval $(\mathrm{CI})]=0.97[0.63-1.48], p=$ 0.880). After simple stratification by advanced maternal age or parity (Additional file 2: Table S2), ORs of association between bonding disorders and $\mathrm{CL} / \mathrm{P}$ in multivariate logistic regression analyses tended to be decreased in mothers aged $<35(\mathrm{OR}[95 \% \mathrm{CI}]=0.71$
[0.40-1.24], $p=0.222)$ or primiparae (OR [95\% CI] $=0.58$ [0.28-1.22], $p=0.152$ ), while they tended to be increased in mothers aged $\geq 35$ (OR $[95 \% \mathrm{CI}]=1.81[0.91-3.61]$, $p=0.086$ ) or multiparae (OR [95\% CI] $=1.39[0.82-2.35]$, $\mathrm{p}=0.222)$. Thus, the dataset was used after stratification with a combination of maternal age and parity. The characteristics of participants after stratification are shown in Table 1.

In multivariate logistic regression analysis using the imputed dataset, the adjusted ORs $(95 \% \mathrm{CI})$ for bonding disorders of mothers of infants with $\mathrm{CL} / \mathrm{P}$ in each group are summarized in Table 2. Compared with the reference participants with healthy infants, analyses without adjustments (crude model) or adjusted for all covariates except for maternal depression (model 1) revealed that the prevalence of bonding disorders was significantly associated with having an infant with $\mathrm{CL} / \mathrm{P}$ only in the advanced-age multiparae group (OR $[95 \% \mathrm{CI}]=2.51$ [1.17-5.37], $p=0.018$ ), but not in the other groups (OR [95\% CI]: $0.44[0.18-1.09], p=0.076$ in younger primiparae; 1.03 [0.51-2.07], $p=0.946$ in younger multiparae; and 1.14 [0.61-2.15], $p=0.836$ in advanced-age primiparae, respectively, in Table 2). However, additional adjustment for maternal depression (model 2) weakened the statistical association and resulted in no significance between bonding disorders and CL/P among advancedage multiparae (OR $[95 \% \mathrm{CI}]=2.18$ [0.96-4.95], $p=$ 0.062 ). Interestingly, though not significant, $C L / P$ tended to be negatively associated with bonding disorders only among young primiparae (OR $[95 \% \mathrm{CI}]=0.44[0.18-$ 1.12], $p=0.085)$. Furthermore, analyses of the complete dataset $(n=75,361)$, excluding cases with missing values, also indicated significant association between bonding disorders and CL/P in crude model (OR [95\% CI]; 2.39 [1.04-5.51], $p=0.040$ ), but not in other models as shown in Additional file 3: Table S3. There were no significant interaction terms in the model between advanced maternal age and parity.

\section{Association between bonding disorders and cleft lip prevalence}

With respect to the association of bonding disorders with the visibility of cleft lip, the prevalence of bonding

Table 3 Association of bonding disorders with the prevalence of cleft lip among advanced-age multiparae

\begin{tabular}{|c|c|c|c|c|c|}
\hline$\geq 35$, Multiparae & Healthy $(n=15,072)$ & $\mathrm{CL} \pm \mathrm{P}(n=29)$ & $p$ value & $\mathrm{CP}(n=8)$ & $p$ value \\
\hline Bonding Disorders, $n(\%)$ & $1503(10.0)$ & $7(24.1)$ & & $2(25.0)$ & \\
\hline Crude & 1.00 & $2.87(1.86-4.44)$ & 0.015 & $3.01(1.33-6.81)$ & 0.178 \\
\hline Model $1^{\text {a }}$ & 1.00 & $2.56(1.07-6.10)$ & 0.033 & $2.36(0.46-11.95)$ & 0.308 \\
\hline Model $2^{\mathrm{b}}$ & 1.00 & $2.31(0.93-5.73)$ & 0.072 & $1.76(0.28-10.93)$ & 0.545 \\
\hline
\end{tabular}

Odds ratio (95\% confidence interval) (all such values) for bonding disorders were compared with the reference participants

${ }^{a}$ Adjusted for maternal factors (smoking and drinking habits, feeding pattern, and infant sex)

${ }^{b}$ Additionally adjusted for maternal depression with Model 1

$P$ values representing significant differences $(<0.05)$ are indicated in bold 
disorders among advanced-age multiparae was significantly associated with $\mathrm{CL} \pm \mathrm{P}$ in the crude model (OR [95\% CI]; 2.87 [1.86-4.44], $p=0.015$ ) or model 1 (OR [95\% CI]; $2.56[1.07-6.10], p=0.033)$, but not in adjusted model for all covariates (OR [95\% CI]; 2.31 [0.935.73], $p=0.072$ ) as shown in Table 3. CP, a group with less visible issues than $\mathrm{CL} \pm \mathrm{P}$ did not also have any significant association with bonding disorders (OR [95\% CI]; 1.76 [0.28-10.93], $p=0.545$ ). In addition, there were no significant associations between bonding disorders with $\mathrm{CL} \pm \mathrm{P}$ or $\mathrm{CP}$ in the other three groups (younger primiparae, younger multiparae. or advanced-age primiparae).

\section{Discussion}

Our present results using the nationwide data from a large-scale birth cohort study in Japan showed no significant association between maternal bonding disorders and CL/P among all the participants (OR [95\% $\mathrm{CI}$; 0.97 [0.63-1.48], $p=0.880$ ). However, our finding revealing the significant association of $\mathrm{CL} / \mathrm{P}$ with maternal bonding disorders among advanced-age multiparae may serve as valuable information for multidisciplinary cleft care providers in terms of the practical benefits of the MIBS in screening for maternal bonding issues.

To the best of our knowledge, this is the first report showing the association of $\mathrm{CL} / \mathrm{P}$ with motherto-infant bonding, though only among advanced-age multiparae. Maternal depression, which has been acknowledged as a predictor for bonding disorders [23, 24 ], statistically impacts the association of maternal bonding disorders with $\mathrm{CL} / \mathrm{P}$, because mothers of infants with $\mathrm{CL} / \mathrm{P}$ are generally troubled with more parenting and/or caregiving issues with regard to feeding and breathing developments [5-7]. Furthermore, because the visual impacts of cleft lip possibly influence the processing of maternal-to-infant bonding as suggested by Boztepe et al. [12], we focused on whether the prevalence of cleft lip was associated with bonding disorders among advanced-age multiparae. Consequently, the significant association of bonding disorders with prevalence of $\mathrm{CL} \pm \mathrm{P}$ did not remain after the adjustment using all covariates (OR $[95 \% \mathrm{CI}]=2.31[0.93-5.73], p=0.072)$. This finding may be due to the smaller sample size of mothers having infants with CL/P. Further examination of the confounding effects by visibility of cleft lip in future studies with the appropriate design is warranted.

Our results indicated that the association between bonding disorders and $\mathrm{CL} / \mathrm{P}$ strongly varies according to parity and maternal age at delivery. Similar to the increasing trends of advanced maternal age and multiple parity on the association between bonding disorders and
$\mathrm{CL} / \mathrm{P}$ (Additional file 2: Table S2), their combined stratification showed a significant association between bonding disorders and $\mathrm{CL} / \mathrm{P}$ among advanced-age multiparae. A review of relevant studies indicated that the impacts of advanced maternal age and/or parity on mother-toinfant bonding are under some debate; however, several studies have reported adverse effects of older maternal age and multiparity on mother-to-infant bonding [3437]. Older mothers generally experience a more severe delivery and have more issues regarding parenting due to physical and psychological limitations [38, 39]. Meanwhile, as shown in our results (Table 1), multiparity generally contributes to better mother-to-infant bonding $[40,41]$. Therefore, we speculated that the significant association $\mathrm{CL} / \mathrm{P}$ and bonding disorders among between multiparous mothers may be related to the presence of healthy siblings. It should be noted that the recurrence rate of nonsyndromic $\mathrm{CL} / \mathrm{P}$ among siblings is reportedly low, 3.2-9.1\% [42, 43]. Similarly, Van Horne et al. reported that child maltreatment among children with $\mathrm{CL} /$ $P$ increases as the number of siblings increases [11]. Tanimura et al., using nationwide data in Japan, pointed out that sibling comparison by parents (potentially including caregiving with congenital anomalies) may be a common risk factor for child maltreatment [44]. Differences in caregiving among siblings adversely impact maternal feelings and behaviours toward infants with $\mathrm{CL} / \mathrm{P}$, whose care typically involves more daily-life stressors [45], and may lead to maternal bonding issues. In order to further examine these findings, careful longitudinal observations among mothers of infants with $\mathrm{CL} / \mathrm{P}$ are necessary because there may be potential impacts on the children's development with $\mathrm{CL} / \mathrm{P}$ from maternal feelings and/or behaviours, even when the mother is giving birth to a new healthy sibling.

This study has several strengths and limitations. Since the Japanese nationwide survey covered approximately $45 \%$ of infants born in multi-subject area during 2013, our results, mostly based on the Japanese general population, allowed us to compare the experimental participants with abundant controls [27]. In terms of study limitations, first, this was a cross-sectional study using a one-time measurement of mother-to-infant bonding as the outcome. Future longitudinal studies with more appropriate designs that consider episodes of child maltreatment are warranted. Second, this study's data collection methods did not include a query about antenatal diagnosis and/or screening. Johns et al. suggested that receiving antenatal diagnosis decreases maternal depressive symptoms among mothers of infants with $\mathrm{CL} / \mathrm{P}$ [9]. Thus, our findings may be limited because the possibility of artificial abortion related to congenital anomaly after antenatal diagnosis as a selection bias cannot be ruled out. 


\section{Conclusions}

This cross-sectional study using Japanese nationwide data indicated that mothers of infants with $\mathrm{CL} / \mathrm{P}$ had similar rates of bonding disorders as the general population; however, advanced-age multiparae had a significantly higher risk of bonding disorders, and the MIBS may be useful in understanding antecedents of their bonding issues.

\section{Supplementary information}

Supplementary information accompanies this paper at https://doi.org/10. 1186/s12887-019-1877-9.

Additional file 1: Table S1. Total basic characteristics of participating mothers

Additional file 2: Table S2. Association of bonding disorders with the prevalence of $C L / P$ with stratification either by maternal age or by parity

Additional file 3: Table S3. Association of bonding disorders with $C L / P$ among advanced-age multiparae in complete dataset analysis

\section{Abbreviations}

Cl: Confidence interval; $C L \pm P$ : Cleft lip with or without cleft palate; CL/ P: Cleft lip and/or cleft palate; CP: Isolated cleft palate; IQR: Interquartile range; JECS: Japan Environment and Children's Study; K6: Kessler Psychological Distress Scale scores; MIBS: Mother-to-Infant Bonding Scale; OR: Odds ratio; SD: Standard deviation

\section{Acknowledgements}

We would like to express our gratitude to all of the JECS study participants and to the JECS staff members for conducting the procedure and helping with the data analysis.

The 2019 members of JECS were as follows: Members of the JECS (principal investigator, Michihiro Kamijima) as of 2019: Shin Yamazaki (National Institute for Environmental Studies, Tsukuba, Japan), Yukihiro Ohya (National Center for Child Health and Development, Tokyo, Japan), Reiko Kishi (Hokkaido University, Sapporo, Japan), Nobuo Yaegashi (Tohoku University, Sendai, Japan), Koichi Hashimoto (Fukushima Medical University, Fukushima, Japan), Chisato Mori (Chiba University, Chiba, Japan), Shuichi Ito (Yokohama City University, Yokohama, Japan), Zentaro Yamagata (University of Yamanashi, Chuo, Japan), Hidekuni Inadera (University of Toyama, Toyama, Japan), Michihiro Kamijima (Nagoya City University, Nagoya, Japan), Takeo Nakayama (Kyoto University, Kyoto, Japan), Hiroyasu Iso (Osaka University, Suita, Japan), Masayuki Shima (Hyogo College of Medicine, Nishinomiya, Japan), Youich Kurozawa (Tottori University, Yonago, Japan), Narufumi Suganuma (Kochi University, Nankoku, Japan), Koichi Kusuhara (University of Occupational and Environmental Health, Kitakyushu, Japan), and Takahiko Katoh (Kumamoto University, Kumamoto, Japan).

\section{Authors' contributions}

HM, RN, TA, and NY participated in data acquisition. ST, MT, and HM developed the study concept and participated in its design. TK, KI, and RN helped develop the study concept. ST, MT, and HM critically revised the manuscript. All authors have read and approved the final version of the manuscript.

\section{Funding}

The Japan Environment and Children's Study was funded by the Ministry of the Environment, Japan. The findings and conclusions of this article are solely the responsibility of the authors and do not represent the official views of the above government.

\section{Availability of data and materials}

The JECS data are not publicly available due to ethical restrictions and the legal framework of Japan. All inquiries about access to the data should be sent to the JECS Programme Office, National Institute for Environmental Studies (jecs-en@nies.go.jp).

\section{Ethics approval and consent to participate}

This study was conducted in accordance with the World Medical Association Declaration of Helsinki. The JECS protocol was approved by the Ministry of the Environment's Institutional Review Board on Epidemiological Studies (no. 100406001), and approved by the ethics committees of all participating institutions (i.e., Asahikawa Medical College, Chiba University, Doshisha University, Fukushima Medical University, Hokkaido University, Hyogo College of Medicine, Japanese Red Cross Hokkaido College of Nursing, Kochi University, Kumamoto University, Kyoto University, Kyushu University, Nagoya City University, NCCHD, NIES, Osaka Medical Center and Research Institute for Maternal and Child Health, Osaka University, Sapporo Medical University, Shinshu University, Tohoku University, Tottori University, University of Occupational and Environmental Health, University of Miyazaki, University of the Ryukyu, University of Toyama, University of Yamanashi, and Yokohama City University). Written informed consent was obtained from all participants. The present study was conducted as a part of JECS and used anonymized data; hence, additional approval from the ethics committee was not required.

\section{Consent for publication}

Not applicable.

\section{Competing interests}

The authors declare that they have no competing interests.

\section{Author details}

${ }^{1}$ Department of Orthodontics and Speech Therapy for Craniofacial Anomalies, Tohoku University Hospital, Sendai, Miyagi 980-8574, Japan. ${ }^{2}$ Department of Nursing, Tohoku Fukushi University, 6-149-1 Kunimi-ga-oka, Aoba-ku, Sendai, Miyagi 981-3201, Japan. ${ }^{3}$ Department of Medicine and Science in Sports and Exercise, Tohoku University Graduate School of Medicine, Sendai, Miyagi 980-8575, Japan. ${ }^{4}$ Division of Preventive Dentistry, Tohoku University Graduate School of Dentistry, Sendai, Miyagi 980-8575, Japan. ${ }^{5}$ Division of Craniofacial Anomalies, Tohoku University Graduate School of Dentistry, Sendai, Miyagi 980-8575, Japan. ${ }^{6}$ Division of Biomedical Engineering for Health \& Welfare, Tohoku University Graduate School of Biomedical Engineering, Sendai, Miyagi 980-8575, Japan. ${ }^{7}$ Department of Informative Genetics, Environment and Genome Research Center, Tohoku University Graduate School of Medicine, Sendai, Miyagi 980-8575, Japan. ${ }^{8}$ Department of Obstetrics and Gynecology, Tohoku University Graduate School of Medicine, Sendai, Miyagi 980-8575, Japan.

Received: 2 December 2019 Accepted: 5 December 2019

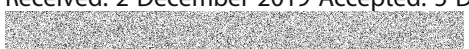

\section{References}

1. The Centre of the International Clearinghouse for Birth Defects Surveillance and Research. Annual Report 2014. In. Roma, Italy: The Centre of the International Clearinghouse for Birth Defects Surveillance and Research; 2014.

2. Natsume N, Kawai T, Kohama G, Teshima T, Kochi S, Ohashi Y, et al. Incidence of cleft lip or palate in 303738 Japanese babies born between 1994 and 1995. Br J Oral Maxillofac Surg. 2000;38:605-7.

3. Mezawa H, Tomotaki A, Yamamoto-Hanada K, Ishitsuka K, Ayabe T, Konishi $\mathrm{M}$, et al. Prevalence of congenital anomalies in the Japan environment and Children's study. J Epidemiol. 2018

4. Bekisz JM, Fryml E, Flores RL. A review of randomized controlled trials in cleft and craniofacial surgery. J Craniofac Surg. 2018;29:293-301.

5. Takemura H, Yasumoto K, Toi T, Hosoyamada A. Correlation of cleft type with incidence of perioperative respiratory complications in infants with cleft lip and palate. Paediatr Anaesth. 2002;12:585-8.

6. Ize-lyamu IN, Saheeb BD. Feeding intervention in cleft lip and palate babies: a practical approach to feeding efficiency and weight gain. Int J Oral Maxillofac Surg. 2011:40:916-9.

7. Gottschlich MM, Mayes T, Allgeier C, James L, Khoury J, Pan B, et al. A retrospective study identifying breast Milk feeding disparities in infants with cleft palate. J Acad Nutr Diet. 2018;118:2154-61.

8. Montirosso R, Fedeli C, Murray L, Morandi F, Brusati R, Perego GG, et al. The role of negative maternal affective states and infant temperament in early interactions between infants with cleft lip and their mothers.J Pediatr Psychol. 2012;37:241-50. 
9. Johns AL, Hershfield JA, Seifu NM, Haynes KA. Postpartum depression in mothers of infants with cleft lip and/or palate. J Craniofac Surg. 2018;29:e354-8.

10. Van Horne BS, Caughy MO, Canfield M, Case AP, Greeley CS, Morgan R, et al. First-time maltreatment in children ages 2-10 with and without specific birth defects: a population-based study. Child Abuse Negl. 2018;84: 53-63.

11. Van Horne BS, Moffitt KB, Canfield MA, Case AP, Greeley CS, Morgan R, et al. Maltreatment of children under age 2 with specific birth defects: a population-based study. Pediatrics. 2015;136:e1504-12.

12. Boztepe $H$, Ay A, Kerimoglu Yildiz G, Cinar S. Does the visibility of a congenital anomaly affect maternal-infant attachment levels? J Spec Pediatr Nurs. 2016;21:200-11.

13. Borghini A, Despars J, Habersaat S, Turpin H, Monnier M, Ansermet F, et al. Attachment in infants with cleft lip and/or palate: marginal security and its changes over time. Infant Ment Health J. 2018;39:242-53.

14. Coy K, Speltz ML, Jones K. Facial appearance and attachment in infants with orofacial clefts: a replication. Cleft Palate Craniofac J. 2002;39:66-72.

15. Despars J, Peter C, Borghini A, Pierrehumbert B, Habersaat S, Muller-Nix C, et al. Impact of a cleft lip and/or palate on maternal stress and attachment representations. Cleft Palate Craniofac J. 2011;48:419-24.

16. Bowlby J. The nature of the child's tie to his mother. Int J Psychoanal. 1958; 39:350-73.

17. Kumar RC. "Anybody's child": severe disorders of mother-to-infant bonding. Br J Psychiatry. 1997;171:175-81.

18. Matsunaga A, Takauma F, Tada K, Kitamura T. Discrete category of motherto-infant bonding disorder and its identification by the mother-to-infant bonding scale: a study in Japanese mothers of a 1-month-old. Early Hum Dev. 2017;111:1-5

19. Brockington IF, Fraser C, Wilson D. The postpartum bonding questionnaire: a validation. Arch Womens Ment Health. 2006:9:233-42.

20. Brancato A, Cannizzaro C. Mothering under the influence: how perinatal drugs of abuse alter the mother-infant interaction. Rev Neurosci. 2018;29: 283-94.

21. Choi H, Yamashita T, Wada $Y$, Narumoto J, Nanri H, Fujimori A, et al. Factors associated with postpartum depression and abusive behavior in mothers with infants. Psychiatry Clin Neurosci. 2010;64:120-7.

22. Yoshida K, Yamashita H, Conroy S, Marks M, Kumar C. A Japanese version of mother-to-infant bonding scale: factor structure, longitudinal changes and links with maternal mood during the early postnatal period in Japanese mothers. Arch Womens Ment Health. 2012;15:343-52.

23. Badr LK, Ayvazian N, Lameh S, Charafeddine L. Is the effect of postpartum depression on mother-infant bonding universal? Infant Behav Dev. 2018;51: 15-23.

24. Ohara $M$, Nakatochi $M$, Okada $T$, Aleksic B, Nakamura $Y$, Shiino $T$, et al. Impact of perceived rearing and social support on bonding failure and depression among mothers: a longitudinal study of pregnant women. J Psychiatr Res. 2018;105:71-7.

25. Caldas IFR, Garotti MF, Shiramizu VKM, Pereira A. The socio-communicative development of preterm infants is resistant to the negative effects of parity on maternal responsiveness. Front Psychol. 2018;9:43.

26. Mirhosseini H, Moosavipoor SA, Nazari MA, Dehghan A, Mirhosseini S, Bidaki $\mathrm{R}$, et al. Cognitive behavioral development in children following maternal postpartum depression: a review article. Electron Physician. 2015;7:1673-9.

27. Kawamoto T, Nitta H, Murata K, Toda E, Tsukamoto N, Hasegawa M, et al. Rationale and study design of the Japan environment and children's study (JECS). BMC Public Health. 2014;14:25.

28. Michikawa T, Nitta H, Nakayama SF, Yamazaki S, Isobe T, Tamura K, et al. Baseline profile of participants in the Japan environment and Children's study (JECS). J Epidemiol. 2018;28:99-104.

29. Yokoyama Y, Takachi R, Ishihara J, Ishii Y, Sasazuki S, Sawada N, et al. Validity of short and long self-administered food frequency questionnaires in ranking dietary intake in middle-aged and elderly Japanese in the Japan public health center-based prospective study for the Next generation (JPHC-NEXT) protocol area. J Epidemiol. 2016;26:420-32.

30. Watanabe Z, Iwama N, Nishigori H, Nishigori T, Mizuno S, Sakurai K, et al. Psychological distress during pregnancy in Miyagi after the great East Japan earthquake: the Japan environment and Children's study. J Affect Disord. 2016;190:341-8

31. Berg E, Lie RT, Sivertsen A, Haaland OA. Parental age and the risk of isolated cleft lip: a registry-based study. Ann Epidemiol. 2015;25:942-947 e941.
32. Cummings P. Missing data and multiple imputation. JAMA Pediatr. 2013; 167:656-61.

33. Rubin DB, Schenker N. Multiple imputation in health-care databases: an overview and some applications. Stat Med. 1991;10:585-98.

34. Rossen L, Hutchinson D, Wilson J, Burns L, Allsop S, Elliott EJ, et al. Maternal bonding through pregnancy and postnatal: findings from an Australian longitudinal study. Am J Perinatol. 2017;34:808-17.

35. Ustunsoz A, Guvenc G, Akyuz A, Oflaz F. Comparison of maternal-and paternal-fetal attachment in Turkish couples. Midwifery. 2010;26:e1-9.

36. Condon JT, Esuvaranathan V. The influence of parity on the experience of pregnancy: a comparison of first- and second-time expectant couples. $\mathrm{Br}$ Med Psychol. 1990;63(Pt 4):369-77.

37. van Bakel HJ, Maas AJ, Vreeswijk CM, Vingerhoets AJ. Pictorial representation of attachment: measuring the parent-fetus relationship in expectant mothers and fathers. BMC Pregnancy Childbirth. 2013:13:138.

38. Mori E, Tsuchiya M, Maehara K, Iwata H, Sakajo A, Tamakoshi K. Fatigue, depression, maternal confidence, and maternal satisfaction during the first month postpartum: a comparison of Japanese mothers by age and parity. Int J Nurs Pract. 2017;23.

39. Iwata H, Mori E, Sakajo A, Aoki K, Maehara K, Tamakoshi K. Prevalence of postpartum depressive symptoms during the first 6 months postpartum: association with maternal age and parity. J Affect Disord. 2016;203:227-32.

40. Tsuchida A, Hamazaki K, Matsumura K, Miura K, Kasamatsu H, Inadera H, et al. Changes in the association between postpartum depression and mother-infant bonding by parity: longitudinal results from the Japan environment and Children's study. J Psychiatr Res. 2019;110:110-6.

41. Nakano M, Upadhyaya S, Chudal R, Skokauskas N, Luntamo T, Sourander A, et al. Risk factors for impaired maternal bonding when infants are 3 months old: a longitudinal population based study from Japan. BMC Psychiatry. 2019:19:87.

42. Grosen D, Chevrier C, Skytthe A, Bille C, Molsted K, Sivertsen A, et al. A cohort study of recurrence patterns among more than 54,000 relatives of oral cleft cases in Denmark: support for the multifactorial threshold model of inheritance. J Med Genet. 2010;47:162-8.

43. Klotz CM, Wang X, Desensi RS, Grubs RE, Costello BJ, Marazita ML. Revisiting the recurrence risk of nonsyndromic cleft lip with or without cleft palate. Am J Med Genet A. 2010;152A:2697-702.

44. Tanimura M, Matsui I, Kobayashi N. Child abuse of one of a pair of twins in Japan. Lancet. 1990;336:1298-9.

45. Pedersen MS, Wehby GL, Pedersen DA, Christensen K. Long-term effects of oral clefts on health care utilization: a sibling comparison. Eur J Health Econ. 2015:16:603-12

\section{Publisher's Note}

Springer Nature remains neutral with regard to jurisdictional claims in published maps and institutional affiliations.
Ready to submit your research? Choose BMC and benefit from:

- fast, convenient online submission

- thorough peer review by experienced researchers in your field

- rapid publication on acceptance

- support for research data, including large and complex data types

- gold Open Access which fosters wider collaboration and increased citations

- maximum visibility for your research: over $100 \mathrm{M}$ website views per year

At BMC, research is always in progress.

Learn more biomedcentral.com/submissions 